\title{
COMPARATIVE STUDY ON EARLY ONSET AND LATE ONSET ALCOHOL DEPENDENCE PATIENTS
}

\author{
M. S. Karthik1, N. Prabhu², V. Subashini', R. Balakrishnan ${ }^{3}$, R. Sathianathan ${ }^{4}$ \\ ${ }^{1}$ Assistant Professor, Department of Psychiatry, Sri Ramachandra University, Chennai. \\ ${ }^{2}$ Assistant Professor, Department of Psychiatry, Sivagangai Medical College, Sivagangai, Tamilnadu. \\ ${ }^{3}$ Senior Resident, Department of Psychiatry, Sri Ramachandra University, Chennai. \\ 4 Professor, Department of Psychiatry, Sri Ramachandra University, Chennai. \\ 5Professor, Department of Psychiatry, Sri Ramachandra University, Chennai.
}

\section{ABSTRACT}

\section{CONTEXT}

Early onset of alcohol use is a major public health concern in terms of its impact on adolescent morbidity and mortality.

\section{AIM}

Comparative study of early and late onset alcohol dependent patients with their correlates such as demographics, family history of alcohol dependence, severity of dependence, and alcohol-induced psychiatric disorders.

\section{SETTINGS AND DESIGN}

Cross-sectional descriptive study conducted in the Department of Psychiatry, Sri Ramachandra Medical College and Research Institute.

\section{MATERIALS AND METHODS}

A cross-sectional assessment was done in two groups of 50 patients each. Patients with age at onset of alcoholic dependence less than 25 years were allocated to the early onset group and those patients with age at onset of dependence more than 25 years were allocated to the late onset group.

\section{STATISTICAL ANALYSIS:}

The data thus collected was analysed using SPSS version 14.

\section{RESULTS}

The study demonstrated a statistically significant difference pertaining to the duration and severity of alcohol dependence, which was more in patients with early onset alcohol dependence when compared to the late onset group. In addition to this, family history of alcohol dependence was positive in more patients belonging to the early onset group. However, there was no significant difference in the prevalence of alcohol-induced psychiatric disorders between the two groups.

\section{CONCLUSION}

This study demonstrates that the severity and duration of alcohol dependence was significantly more in patients with early onset alcohol dependence.

\section{KEYWORDS}

Alcohol Dependence Severity, Early Onset, Late Onset.

HOW TO CITE THIS ARTICLE: Karthik MS, Prabhu N, Subashini V, et al. Comparative study on early onset and late onset alcohol dependence patients. J. Evolution Med. Dent. Sci. 2016;5(57):3908-3912, DOI: 10.14260/jemds/2016/895

\section{INTRODUCTION}

The national epidemiological survey done on the new DSM-5 classification of Alcohol Use Disorders(AUDs) from April 2012 to July 2013 found the twelve-month and lifetime prevalence of AUDs to be $13.9 \%$ and $29.1 \%$, respectively. Among those who had AUDs, $26.7 \%$ of twelve-month prevalence and $37.0 \%$ of lifetime prevalence were younger than 18 years of age.[1]

Financial or Other, Competing Interest: None.

Submission 24-06-2016, Peer Review 08-07-2016,

Acceptance 11-07-2016, Published 16-07-2016.

Corresponding Author:

Dr. Karthik M.S,

Assistant Professor,

Department of Psychiatry,

Sri Ramachandra University,

Chennai-600116.

E-mail: drkarthikms2008@gmail.com

DOI: 10.14260/jemds/2016/895
From the earlier national epidemiological survey, it was noted that the rate of lifetime dependence was more than $40 \%$ among individuals who started drinking at 14 years of age or younger compared to $10 \%$ among those who started drinking at 20 years of age or older and the odds of dependence decreased by $14 \%$ with each increasing year of age at the onset of use.[2] Another study also found that early onset of drinking enhances the risk of further heavy drinking in adulthood; however, the association was not statistically significant.[3]

More than one third of unintentional injuries to themselves and to others occurred in persons under the influence of alcohol who were under 25 years of age.[4] A cross-sectional national survey reported that early onset of drinking was associated with a greater likelihood of being injured and being in traffic accidents. $[4,5]$ Those who started drinking early were more likely to experience a chronic and relapsing type of dependence, which is characterised by frequent and longer episodes of dependence and more severe symptoms of 
dependence. ${ }^{[6]}$ Several studies in the past have indicated that the earlier the people start to drink it is more likely that they would develop alcohol dependence within 10 years of onset and before the age of $25 .[2,4,6]$ When compared to those who were diagnosed as dependent at 30 years of age or older, those who become dependent by 18 years of age are less likely to seek treatment for alcohol-related complications. [7] A history of addiction in the parents is a strong predictor of AUDs and drug dependence in their offspring and enhances the severity of symptoms.[8] Maternal AUDs increase the probability of progression from occasional drinking to regular use whereas paternal AUDs were associated with progression from regular drinking to hazardous use. Parental alcoholism enhanced the risk for early onset of harmful drinking and alcohol dependence in their children between 14-17 years of age and also results in early onset of adverse outcomes in them. [9]

A review article from Indian studies on the prevalence of various psychiatric co-morbidities among AUDs have reported that mood, anxiety, psychotic, and psychosexual disorders are commonly co-prevalent with AUDs.[10] Studies on the effect of age at onset of drinking on AUDs and their severity are quiet numerous in western research; however, similar studies are sparse and limited in Indian research. The only study similar to our study was published by Varma et al. in 1994.[11] Therefore, the current study is aimed at comparing early and late onset alcohol dependent patients in terms of their demographics, family history of alcohol dependence, severity of dependence, and alcohol-induced psychiatric disorders, which would add valuable information to the existing western literature from an Indian perspective.

\section{MATERIALS AND METHODS \\ Design}

This cross-sectional descriptive study was conducted at the Department of Psychiatry, Sri Ramachandra Medical College and Research Institute (SRMC AND RI), Chennai. The study has got institutional ethical committee approval, which is in standard with the Helsinki Declaration of 1975 that was revised in 2000. Informed written consent was obtained from all participants prior to inclusion in the study and other ethical standards were maintained in the study.

\section{PARTICIPANTS}

\section{Inclusion Criteria}

Patients aged more than 18 years who fulfilled the DSM IV diagnosis of alcohol dependence as per Structured Clinical Interview for DSM-IV Axis I Disorders-Clinical Version.[12] (SCID CV) were included in the study. The patients who fulfilled the criteria for dependence before the age of 25 years were classified as early onset alcohol dependence patients and those who fulfilled the criteria at an age more than 25 years were allocated to the late onset group.

\section{Exclusion Criteria}

Patients with other substance dependence (Except alcohol and nicotine), with major comorbid psychiatric illness and with any major physical illness who were too ill to participate in the study were excluded.

\section{Assessments}

Over a period of one year, 50 patients in each group were collected. The sociodemographic data such as age, marital status, occupation, income, religion collected using a semi- structured proforma, and clinical profile details such as age at onset of drinking, duration of drinking, age at onset of dependence, nature of alcohol, and family history of alcohol dependence were obtained from the patients who gave their consent for participating in this study. In addition to this, the patients from both groups were also assessed for alcoholinduced psychiatric disorders and their types by using SCIDCV. Finally, the severity of alcohol dependence was assessed using the Severity of Alcohol Dependence QuestionnaireSADQ. ${ }^{[13]}$ which is a 20 -item questionnaire in which each item is scored from 0 to 3. 0 -almost never, 1-sometimes, 2-often, and 3-nearly always. The scores of all the 20 items were summed up and the severity of alcohol dependence were graded as follows. 0-3=no dependence, 4-19=mild dependence, 20-30=moderate dependence, 31-44=severe dependence, and 45 and above as very severe dependence.

\section{Analysis}

Data was analysed using the Statistical Package for Social Scientists, version fourteen (SPSS-14 - SPSS Inc., Chicago, IL, USA). Frequency counts were obtained for all the discrete variables. Mean and standard deviation were computed for all the continuous variables. Chi-square test and unpaired Student's t test were used to compare the two groups based on different parameters. Two tailed $\mathrm{P}$ values were used for checking significance.

\section{RESULTS}

The demographics, clinical profiles, and family history of alcohol dependence in both groups are depicted in tables 1 and 2 , respectively.

Patients in the early onset group were mostly young adults, school dropouts, who hailed from an urban background and belonged to lower socioeconomic strata. In the late onset group, most of the patients were middle-aged males who had completed their graduation and schooling hailed from an urban background and belonged to lower to middle socioeconomic strata.

Patients in the early onset group had begun drinking at an average age of 17 years and the mean duration of drinking was 16 years. Many were dependent drinkers by the age of 21 . The late onset group patients had begun drinking at a later age of 24 years on an average with a mean duration of drinking of 18 years and established a dependent pattern of drinking at the age of 36 years. Almost, $96 \%$ to $98 \%$ of the patients in both groups were drinking brandy with an occupational impairment in $62 \%$ to $66 \%$ of patients. Family history of alcohol dependence was more prevalent among the early onset group (64\%) when compared to the late onset group (30\%).

\begin{tabular}{|c|c|c|}
\hline $\begin{array}{c}\text { Socio-demographic } \\
\text { Variable }\end{array}$ & $\begin{array}{c}\text { Early Onset } \\
\text { Group } \\
\text { (N=50) } \\
\text { N (\%)/Mean } \\
\text { (SD) }\end{array}$ & $\begin{array}{c}\text { Late Onset } \\
\text { Group } \\
\text { (N=50) } \\
\text { N (\%)/Mean } \\
\text { (SD) }\end{array}$ \\
\hline Age & $\begin{array}{c}34.70 \\
( \pm 9.379)\end{array}$ & $43.58( \pm 7.489)$ \\
\hline Gender & $50(100 \%)$ & $50(100 \%)$ \\
\hline Education & $45(90 \%) /$ & $42(84 \%) /$ \\
School/College & $5(10 \%)$ & $8(16 \%)$ \\
\hline Marital status & $35(70 \%) / 15$ & $47(94 \%) /$ \\
Married/Others & $(15 \%)$ & $3(6 \%)$ \\
\hline
\end{tabular}




\begin{tabular}{|c|c|c|}
\hline $\begin{array}{l}\text { Socioeconomic class } \\
\text { Low/Moderate }\end{array}$ & $\begin{array}{c}42(84 \%) / \\
8(16 \%)\end{array}$ & $\begin{array}{c}33(66 \%) / \\
17(34 \%)\end{array}$ \\
\hline $\begin{array}{l}\text { Occupied } \\
\text { Yes/No }\end{array}$ & $\begin{array}{c}50(100 \%) / \\
0(0 \%)\end{array}$ & $\begin{array}{c}49(98 \%) / \\
1(2 \%)\end{array}$ \\
\hline $\begin{array}{c}\text { Nature of work } \\
\text { Skilled/Unskilled } \\
\text { Clerical }\end{array}$ & $\begin{array}{c}15(30 \%) / \\
32(64 \%) \\
3(6 \%)\end{array}$ & $\begin{array}{c}24(48 \%) / \\
21(42 \%) \\
5(10 \%)\end{array}$ \\
\hline Income & $\begin{array}{c}10,130 \\
( \pm 4,321.1)\end{array}$ & $\begin{array}{c}11,670 \\
( \pm 6,810.6)\end{array}$ \\
\hline $\begin{array}{c}\text { Locality } \\
\text { Urban/Rural }\end{array}$ & $\begin{array}{l}24(48 \%) / \\
26(52 \%)\end{array}$ & $\begin{array}{l}19(38 \%) / \\
31(62 \%)\end{array}$ \\
\hline \multicolumn{3}{|c|}{$\begin{array}{c}\text { Table 1: Socio-demographic Variables of Early Onset } \\
\text { and Late Onset Dependent Group }\end{array}$} \\
\hline
\end{tabular}

\begin{tabular}{|c|c|c|}
\hline $\begin{array}{l}\text { Clinical } \\
\text { Variable }\end{array}$ & $\begin{array}{c}\text { Early Onset } \\
\text { Group (n=50) } \\
\text { n\%/Mean (SD) }\end{array}$ & $\begin{array}{c}\text { Late Onset } \\
\text { Group (n=50) } \\
\text { n\%/Mean (SD) }\end{array}$ \\
\hline $\begin{array}{l}\text { Age of onset of } \\
\text { drinking }\end{array}$ & $17.64( \pm 2.174)$ & $24.84( \pm 6.215)$ \\
\hline Duration of drinking & $16.96( \pm 9.543)$ & $18.92( \pm 8.352)$ \\
\hline $\begin{array}{l}\text { Age of onset of } \\
\text { dependence }\end{array}$ & $21.80( \pm 2.407)$ & $36.78( \pm 5.835)$ \\
\hline Amount consuming & $\begin{array}{c}369.60 \\
( \pm 174.660)\end{array}$ & $393( \pm 180.026)$ \\
\hline $\begin{array}{c}\text { Nature of alcohol } \\
\text { Brandy } \\
\text { Whisky } \\
\text { Others } \\
\end{array}$ & $\begin{array}{c}48(96 \%) \\
2(4 \%) \\
0(0 \%) \\
\end{array}$ & $\begin{array}{c}49(98 \%) \\
0(0 \%) \\
1(2 \%) \\
\end{array}$ \\
\hline $\begin{array}{c}\text { Other substances } \\
\text { Yes/No }\end{array}$ & $\begin{array}{c}47(94 \%) / \\
3(6 \%)\end{array}$ & $\begin{array}{l}44(88 \%) / \\
6(12 \%)\end{array}$ \\
\hline $\begin{array}{l}\text { Occupational } \\
\text { impairment } \\
\text { (Yes/No) }\end{array}$ & $\begin{array}{c}33(66 \%) / \\
17(34 \%)\end{array}$ & $\begin{array}{l}31(62 \%) / \\
19(38 \%)\end{array}$ \\
\hline $\begin{array}{c}\text { Suicidal attempts } \\
\text { Yes/No }\end{array}$ & $\begin{array}{l}5(10 \%) / \\
45(90 \%)\end{array}$ & $\begin{array}{c}4(8 \%) / \\
46(92 \%)\end{array}$ \\
\hline $\begin{array}{c}\text { Family history of } \\
\text { alcohol dependence } \\
\text { (Yes/No) }\end{array}$ & $\begin{array}{c}32(64 \%) / \\
18(36 \%)\end{array}$ & $\begin{array}{l}15(30 \%) / \\
35(70 \%)\end{array}$ \\
\hline \multicolumn{3}{|c|}{$\begin{array}{l}\text { Table 2: Clinical Profile of the Patients in Early Onset } \\
\text { and Late Onset Dependent Group }\end{array}$} \\
\hline
\end{tabular}

Prevalence of Alcohol-Induced Psychiatric Disorders in Early Onset and Late Onset Dependent Group

In the current study, the prevalence of alcohol-induced psychiatric disorders was $40 \%$ in the early onset group, which was slightly more when compared to the late onset group (32\%).

Types of Alcohol-Induced Psychiatric Disorders in Early Onset Dependent Group and Late Onset Dependent Group Among the total prevalence of alcohol-induced psychiatric disorders, delirium constituted $30 \%$ and psychosis constituted $45 \%$ in early onset dependence group. In the late onset group, prevalence of psychosis constituted about 52\% and mood disorders constituted $28 \%$. All the alcohol-induced psychiatric disorders occurred during alcohol usage except the onset of delirium, which manifests usually 24 to 48 hours after the last drink of alcohol. Delirium was seen to be more prevalent in the early onset group when compared to the late onset group. On the other hand, mood disorders had a higher prevalence in the late onset group.
Severity of Alcohol Dependence Questionnaire Scores (SADQ) in early onset dependent group and late onset dependent group

Results obtained from SADQ shows nearly $60 \%$ patients in the early onset group and $40 \%$ in the late onset group were drinking approximately $180 \mathrm{~mL}$ of Indian made foreign liquor (IMFL) every day. About 30\% in the early onset group and 50\% in the late onset group were drinking $375 \mathrm{~mL}$ of IMFL every day and about $10 \%$ to $20 \%$ of patients in early onset group were drinking $750 \mathrm{~mL}$ of IMFL per day. Though all the patients in both groups were experiencing craving, tremors in the hands, and sweating every day, the severity was more in patients in early onset group. Overall, the result from the present study showed that patients in the early onset group had more severe dependence as compared to late onset group. SADQ scores showed that around $70 \%$ of patients in the early onset group were experiencing moderate-to-severe dependence as compared to $90 \%$ of patients in late onset group who were experiencing only mild-to-moderate dependence.

Comparison Statistics between Early Onset and Late Onset Dependent Group

As depicted in the table 3, comparison of the demographics between both the groups found significant differences in the age, marital, and socioeconomic status of the patients. In the clinical profile, significant differences were evident at $P$ value $<0.001$ with regards to their age of onset of drinking as well as their age of development of dependence. In addition, patients in both the groups showed significant difference with $\mathrm{p}$ value $<0.05$ with regards to the amount of alcohol consumed. The family history of alcohol dependence was significantly different between both groups of patients at $p$ value $<0.001$.

\begin{tabular}{|c|c|}
\hline $\begin{array}{c}\text { Socio-demographic } \\
\text { Variable }\end{array}$ & $\begin{array}{c}\text { Chi-square Value } \\
\chi 2 / \text { ' } t \text { ' Value } \\
(\mathrm{df}=98)\end{array}$ \\
\hline Age & $-5.23^{* * *}$ \\
\hline Education & 0.796 \\
\hline Marital status & $9.76^{* *}$ \\
\hline Socioeconomic class & $4.32^{*}$ \\
\hline Occupied & 1.01 \\
\hline Nature of work & 4.86 \\
\hline Income & -1.35 \\
\hline Locality & 1.02 \\
\hline \multicolumn{2}{|c|}{$\begin{array}{c}\text { Table 3: Comparison of Socio-demographic of Patients } \\
\text { between Early and Late Onset Groups }\end{array}$} \\
\hline
\end{tabular}

*** Comparison is significant at the $\mathrm{p}<0.001$ level (2-tailed). ** Comparison is significant at the $\mathrm{p}<0.005$ level (2-tailed).

* Comparison is significant at the $\mathrm{p}<0.05$ level (2-tailed).

\begin{tabular}{|c|c|}
\hline Clinical Variable & $\begin{array}{c}\text { Chi-square Value } \\
\chi 2 / ' t \text { ' Value }(\mathrm{df}=98)\end{array}$ \\
\hline Age of onset of drinking & $-7.73^{* * *}$ \\
\hline Duration of drinking & -2.0 \\
\hline $\begin{array}{l}\text { Age of onset of } \\
\text { dependence }\end{array}$ & $-16.78^{* * *}$ \\
\hline Amount consuming & $-.660 *$ \\
\hline Nature of alcohol & 3.01 \\
\hline $\begin{array}{l}\text { Family history of alcohol } \\
\text { dependence }\end{array}$ & $11.6^{* * *}$ \\
\hline \multicolumn{2}{|c|}{$\begin{array}{c}\text { Table 4: Comparison of Clinical Profile and Family } \\
\text { History of Alcohol Dependence of Patients } \\
\text { Between Two Groups }\end{array}$} \\
\hline
\end{tabular}


*** Comparison is significant at the $\mathrm{p}<0.001$ level (2-tailed)

** Comparison is significant at the $\mathrm{p}<0.005$ level (2-tailed).

* Comparison is significant at the $\mathrm{p}<0.05$ level (2-tailed).

Comparison of Severity of Alcohol Dependence, Prevalence and Types of Alcohol-Induced Psychiatric Disorders between Two Groups

The comparisons between two groups showed that there was significant difference in the SADQ total score at $p$ value $<0.005$, which signifies the severity of alcohol dependence more in early onset dependent group. The prevalence of alcoholinduced psychiatric disorders were slightly more in the early onset group (40\%) than in the late onset group (32\%), but the difference was not statistically significant. Though, the prevalence of psychotic disorders were more in both groups, the prevalence of delirium in the early onset group was significantly higher at $p$ value of $<0.05$, which was five times more than the same in the late onset group.

\begin{tabular}{|c|c|}
\hline Variables & $\begin{array}{c}\text { Chi-square value } \chi 2 \\
(\mathrm{df}=98)\end{array}$ \\
\hline SADQ Total Score & $9.64^{* *}$ \\
\hline $\begin{array}{l}\text { Prevalence of alcohol- } \\
\text { induced psychiatric } \\
\text { disorders }\end{array}$ & .694 \\
\hline \begin{tabular}{ll}
\multicolumn{2}{l}{ Types of Psychiatric } \\
Morbidities \\
1. $\quad$ Delirium \\
2. $\quad$ Psychosis \\
3. $\quad$ Delusional disorder \\
4. $\quad$ Mood disorders \\
5. & Anxiety disorders \\
\end{tabular} & $\begin{array}{c}3.84 * \\
.071 \\
.000 \\
.154 \\
.344\end{array}$ \\
\hline \multicolumn{2}{|c|}{$\begin{array}{c}\text { Table 5: Comparison of Severity of Alcohol Dependence, } \\
\text { Prevalence and Types of Alcohol-Induced Psychiatric } \\
\text { Disorders Between Two Groups }\end{array}$} \\
\hline
\end{tabular}

*** Comparison is significant at the $\mathrm{p}<0.001$ level (2-tailed).

** Comparison is significant at the $\mathrm{p}<0.005$ level (2-tailed).

${ }^{*}$ Comparison is significant at the $\mathrm{p}<0.05$ level (2-tailed).

\section{DISCUSSION}

\section{Methodological Issues}

The current study aimed to compare early and late onset alcohol dependent patients who had been ill for some time, who were randomly selected from a larger group of such patients. All the patients in both groups were male and this is probably secondary to the fact that mostly males seek deaddiction treatment at our centre. In early onset alcohol dependent patients, a majority were school dropouts, unskilled workers, and had more occupational impairment despite being married, which reflects on the social adverse effects of early onset of dependence as compared to late onset alcohol dependent patients.

\section{Age at Onset of Dependence}

In accordance to our aim, we obtained an equal number of samples for both the groups and that shows the heterogeneity of patients attending our centre for treatment. The results of the current study clearly showed that the age of initiation of drinking, age of development of dependence, duration of drinking, and amount of alcohol consumed were significantly different between both groups. A similar pattern has been seen in some previous studies. $[1,2,3,4,6]$
Comparison of Age of Onset of Drinking and Age of Development of Dependence between Early Onset Dependent Group and Late Onset Dependent Group

In accordance to our aim, both groups were statistically significant at $p$ value $<0.001$ with the degree of freedom of 98 in their age of onset of drinking and in the age of development of dependence. In addition, we found that the amount of alcohol consumed by patients of both groups were also significantly different at $p$ value $<0.05$. In the earlier study, it was reported that about $14 \%$ developed dependence among those who began drinking before 14 years of age when compared to only $3 \%$ in individuals who began drinking before 21 years of age. $[4,6]$ They also reported that the incidence of drunken driving, high risk sexual behaviour, unintentional injuries to themselves and others were significantly more in those who started drinking before 14 years of age than who started later than 21 years of age.[6] Many children who experienced overt physical, sexual, or psychological abuse, or whose parents exhibited psychiatric symptoms may start to drink at an earlier age and may drink larger amounts to cope with posttraumatic stress disorder.[1,6,7]

\section{Family History of Alcohol Dependence}

The results of the current study showed patients in the early onset group had twice the family history of dependence as compared to late onset group. The difference was statistically significant at $p$ value $<0.001$. Recent twin study reported that the rate of heritability was $37 \%$ for early age of initiation of drinking and about $62 \%$ for the development of AUDs. In addition, they found that there was no causal relationship between early age of alcohol initiation and alcohol use disorders in their later life and also reported that genetic factors played a role in the early age of initiation as well as AUDs in later life.[14]

\section{Severity of the Alcohol Dependence}

The current study shows that the severity of alcohol dependence was more in early onset group than in the late onset group of patients.

This difference was found to be statistically significant at $p$ value $<0.001$ with degree of freedom of 98 . In line with our results, earlier studies have reported that early onset of drinking and dependence resulted in a chronic relapsing dependence pattern characterised by multiple episodes of dependence, longer duration of episodes, and more symptoms of dependence. $[4,6]$ A study from Brazil reported that early age of dependence enhanced the risk of cannabis use, injuries, physical fights, and poor academic performance.[3]

\section{Rate of Alcohol-Induced Psychiatric Disorders (AIPS)}

The current study found the rate of AIPS was more in the early onset group $40 \%$ as compared to $32 \%$ in the late onset group, but this difference was not statistically significant. A recent review from India that included 35 studies has reported a 26 to $71 \%$ prevalence of mood disorders and 10 to $44 \%$ of anxiety spectrum disorders. They also reported that psychosis and alcoholic hallucinosis are not uncommon.[10]

\section{Limitations}

Though the current study yielded a few positive findings, the following limitations must be kept in mind while interpreting the results. 
Because of a small sample size and inclusion of patients from a single tertiary care centre, the results cannot be readily generalised to community samples. Although, we found an association between family history of dependence and age of onset of dependence, we would not be able to draw any causal inferences unless further longitudinal studies are continued.

\section{CONCLUSIONS}

This study demonstrated that the early onset and late alcohol dependent patients were significantly different in their age of onset of drinking, age of development of dependence, family history of alcohol dependence, and severity of dependence. Both groups were comparable in the occurrence of alcoholinduced psychiatric disorders.

\section{REFERENCES}

1. Grant BF, Goldstein RB, Saha TD, et al. Epidemiology of DSM-V alcohol use disorder: results from the national epidemiologic survey on alcohol and related conditions III. JAMA Psychiatry 2015;72(8):757-66.

2. Grant BF, Dawson DA, Stinson FS, et al. The 12-month prevalence and trends in DSM-IV alcohol abuse and dependence: United States, 1991-1992 and 2001-2002. Drug Alcohol Depend 2004;74(3):223-34.

3. Kuntsche E, Rossow I, Morton SB, et al. Not early drinking, but early drunkenness is a risk factor for problem behaviours among adolescents from 38 European and North American countries. Alcohol Clin Exp Res 2013;37(2):308-14.

4. Hingson RW, Zha W. Age of drinking onset, alcohol use disorders, frequent heavy drinking, and unintentionally injuring oneself and others after drinking. Paediatrics 2009;123(6):1477-84.

5. Vinson DC, Maclure M, Reidinger C, et al. A populationbased case-crossover and case control study of alcohol and the risk of injury. J Stud Alcohol 2003;64(3):358-66.
6. Hingson RW, Heeren T, Winter MR. Age at drinking onset and alcohol dependence: age at onset, duration, and severity. Arch Paediatr Adolesc Med 2006;160(7):739-46.

7. Hingson $\mathrm{R}$, Heeren $\mathrm{T}$, Zakocs $\mathrm{R}$, et al. Age of first intoxication, heavy drinking, driving after drinking, and risk of unintentional injury among U.S. college students. J Stud Alcohol 2003;64(1):23-31.

8. Milne BJ, Caspi A, Harrington $\mathrm{H}$, et al. Predictive value of family history on severity of illness: the case for depression, anxiety, alcohol dependence, and drug dependence. Arch Gen Psychiatry 2009;66(7):738-47.

9. Lieb R, Merikangas KR, Hofler M, et al. Parental alcohol use disorders and alcohol use and disorders in offspring: a community study. Psychol Med 2002;32(1):63-78.

10. Singh S, Balhara YPS. A review of Indian research on cooccurring psychiatric disorders and alcohol use disorders. Indian J Psychol Med 2016;38(1):10-9.

11. Varma VK, Basu D, Malhotra A, et al. Correlates of early and late-onset alcohol dependence. Addict Behav 1994;19(6):609-19.

12. First MB, Spitzer RL, Gibbon M, et al. Structured clinical interview for DSM-IV axis I disorders-clinician version (SCID-CV). Washington, DC. American Psychiatric Press, 1996.

13. Stockwell T, Sitharan T, McGrath D, et al. The measurement of alcohol dependence and impaired control in community samples. Addiction 1994;89(2):167-74.

14. Strom E, Kendler KS, Kjennerud RT. Early age of alcohol initiation is not the cause of alcohol use disorders in adulthood, but is a major indicator of genetic risk. A population-based twin study. Addiction 2014;109(11): 1824-32. 